\title{
The Effect of Radiosensitization of Gemcitabine Related to Suppression of a Repair Pathway: Examination of Mammalian Cells with Therapeutic High Energy X-rays
}

\author{
Keiko Morikawa $^{1,}$, , Yoshida Yukito ${ }^{2}$, Yuh Sugii ${ }^{1}$, Genro Kashino ${ }^{3}$, Hiromu Mori ${ }^{4}$ \\ ${ }^{1}$ Department of Radiological Science, Faculty of Health Sciences, Junshin Gakuen University, Fukuoka, Japan \\ ${ }^{2}$ Oita University Hopspital, Oita, Japan \\ ${ }^{3}$ Advanced Molecular Imaging Center, Faculty of Medicine, Oita University, Oita, Japan \\ ${ }^{4}$ Department of Radiology, Faculty of Medicine, Oita University, Oita, Japan
}

Email address:

morikawa.k@junshin-u.ac.jp (K. Morikawa)

${ }^{*}$ Corresponding author

To cite this article:

Keiko Morikawa, Yoshida Yukito, Yuh Sugii, Genro Kashino, Hiromu Mori. The Effect of Radiosensitization of Gemcitabine Related to Suppression of a Repair Pathway: Examination of Mammalian Cells with Therapeutic High Energy X-rays. American Journal of Laboratory Medicine. Vol. 2, No. 6, 2017, pp. 137-143. doi: 10.11648/j.ajlm.20170206.15

Received: September 11, 2017; Accepted: September 27, 2017; Published: November 7, 2017

\begin{abstract}
Gemcitabine is used in clinical chemo-radiotherapy; however, the mechanism underlying enhanced radiosensitivity by gemcitabine is not fully elucidated. We evaluated the role of gemcitabine in mammalian cell lines using a therapeutic high energy $10 \mathrm{MeV}$ linac-X-ray irradiation device. Rodent cell lines $\mathrm{CHO}$ and xrs 5 were used. A total of $5 \mu \mathrm{M}$ gemcitabine for 24 hours was administered with or without post-X-ray irradiation. DNA double-strand breaks (DSBs) and cell enlargement were observed by using singly gemcitabine. Enhanced cell killing effects by radiotherapy were observed with gemcitabine pre-treatment in both $\mathrm{CHO}$ and xrs5 cells. We focused on the dynamics of phosphorylated p53-binding protein 1 (53BP1)-positive foci after irradiation. Significantly higher numbers of 53BP1 foci were observed after irradiation in gemcitabine pre-treated cells than in untreated cells. The radiosensitizing effect of gemcitabine was not suppressed in the non-homologous end joining (NHEJ) deficient xrs5 cells. We confirmed that in rodent cells the radiosensitizing effect of gemcitabine is related to suppression of a repair pathway other than NHEJ.
\end{abstract}

Keywords: Radiosensitization, Gemcitabine, Non-homologous End Joining, 53BP1

\section{Introduction}

Gemcitabine (4 - amino - 1 - [3, 3 - difluoro - 4 - hydroxyl - 5 - (hydro-xymethyl) tetrahydrofuran $-2-\mathrm{yl}]-1 \mathrm{H}-$ pyrimidin $-2-$ one) is a deoxycytidine analogue that is well known for its anti-tumor activity, and used as a standard therapy for patients with advanced pancreatic cancer. Additionally, it is one of the more effective drugs for sensitization of cells to radiation, because most pancreatic cancers do not respond to gemcitabine alone [1-4]. The radiosensitizing properties of gemcitabine have been demonstrated both in vivo and in vitro [5-13], although the detailed interaction of gemcitabine with radiation has not been elucidated. In preliminary experiments with human lung carcinoma cells, van Putten et al. showed that gemcitabine treatment retards the rate and extent of DNA double-strand break (DSB) repair [14]. In contrast, Lawtence et al. have reported no detectable effect on DNA DSB repair by gemcitabine [15].

DNA DSBs are the major lethal damage caused by radiation. Cells have DNA DSB repair pathways, known as non-homologous end joining (NHEJ) and homologous recombination (HR) [16-19]. To evaluate the involvement of gemcitabine in radiosensitization, we used two cell lines, a wild-type Chinese hamster ovary $(\mathrm{CHO})$ cell line and a $\mathrm{Ku} 80$-deficient $\mathrm{CHO}$ cell line (xrs5) that is deficient in NHEJ repair.

Irradiation of cultured cells has usually been performed using a low dose rate of X-rays, for example, using a 
Gammacell. A Gammacell is an irradiator mounted with Cs-137, which is used widely for biological studies of radiosensitization effects. However, actual radiation therapy is performed with high energy X-ray exposure, such as irradiation from a linear accelerator (Linac). These two types of equipment vary greatly in energy intensity and exposure rate; for instance, $0.514 \mathrm{Mev}$ and $0.74 \mathrm{~Gy} / \mathrm{min}$ from a Gammacell 40 (Atomic Energy of Canada Limited) or $10 \mathrm{Mev}$ and $4.8 \mathrm{~Gy} / \mathrm{min}$ from a Linac-X-ray system (Siemens) (energy intensity and exposure rate, respectively). In this study, we assessed the effect of gemcitabine-induced radiosensitization using a therapeutic high energy X-ray device, a $10 \mathrm{MeV}$ Linac-X-ray irradiation device. To make observations of changes to cells in vivo, we inserted cultured cells in a water equivalent phantom for irradiation. Therefore, this study is designed to reflect actual effects of radiosensitization of gemcitabine to mammalian cells during radiation treatment. This study aimed to reveal changes to cells with time by gemcitabine treatment and/or irradiation using high energy X-rays. Firstly, to visualize the effect of gemcitabine on cells, we calculated size information which indicates shape changes through immunofluorescent staining of nuclei. Next, to confirm the possible role of gemcitabine on radiosensitization, immunofluorescent staining of DNA DSBs was used on a time dependent manner.

\section{Materials and Methods}

\subsection{X-ray Irradiation}

When X-ray energy is high, the point of maximum radiation quantity descends downward from the surface of the absorber. This peak depth was decided using a percentage of depth dose curve determined in a water phantom $(34 \mathrm{~cm} \times 35 \mathrm{~cm} \times 50 \mathrm{~cm}$, Calibration Phantom WP-1D, Germany) with a $10 \times 10 \mathrm{~cm}^{2}$ field at a source-to face distance of $100 \mathrm{~cm}$ for $10 \mathrm{MeV}$ X-rays (PRIMUS Hi-Energy, Siemens, Kemnath, Germany). To make a cell culture environment similar to that in vivo, cultured cells were placed in a water equivalent phantom $(30 \mathrm{~cm} \times 30 \mathrm{~cm}$, Kyoto Kagaku, Japan). To allow for a composition difference between water and the water equivalent phantom, a correction coefficient was derived based on "Standard Dosimetry 01", as determined by the Japan Society of Medical Physics [20]. By measuring the charge amount at the peak depth in water and the water equivalent phantom using a farmer chamber (30013, PTW, Freiburg, Germany), the correction coefficient was determined to enable an actual irradiation dose to be calculated. A corrected irradiation dose, described as a revised monitor unit: MU [cGy], was calculated by a radiotherapy planning device (Pinnacle3 Ver. 8.0, Hitachi Medical Corporation, Tokyo, Japan).

\subsection{Cell Culturing Procedures}

The Chinese hamster ovary (CHO) cell line, and $\mathrm{Ku} 80$-deficient $\mathrm{CHO}$ cells (xrs5) were grown on alpha-MEM medium (Gibco, Invitrogen). All media were supplemented with $10 \%$ bovine calf serum (FBS, Hyclone, South Logan, UT,
USA). The two cell lines were grown as monolayers at $37^{\circ} \mathrm{C}$ in a $5 \% \mathrm{CO}_{2}$ humidified incubator in plastic flasks (Becton Dickinson, Billerica, MA, USA). In a subculturing process, cell numbers were measured to determine the cell proliferation ratio.

\subsection{Treatment of Cells}

Exponentially growing cells were incubated with $5 \mu \mathrm{M}$ gemcitabine (Tokyo Chemical Industry, Japan) for $24 \mathrm{~h}$. A pre-incubation time of $24 \mathrm{~h}$ was adapted to avoid cell cycle stage dependency. After gemcitabine treatment, cells were trypsinized followed by trypsin neutralization with medium. Cell suspensions were diluted in fresh complete medium to a density of approximately $10^{6}$ cells $/ \mathrm{ml}$. To study the effects of radiosensitization, cells were irradiated immediately using a $10 \mathrm{MeV}$ Linac-X-irradiator (Primus, Siemens) at a dose rate of $4.8 \mathrm{~Gy} / \mathrm{min}$, or using a $150 \mathrm{keV}$ super soft X-ray apparatus (SOFTEX, Japan) at a dose rate of $0.635 \mathrm{~Gy} / \mathrm{min}$.

\subsection{Cell Survival}

Cell survival was assessed with a colony formation assay by plating $100 \mu \mathrm{L}$ of appropriately diluted samples to triplicate plastic Petri dishes (Becton Dickinson, NJ, USA), containing $5 \mathrm{ml}$ of complete growth medium. After incubation for 6-8 days, colonies were fixed with $70 \%$ ethanol and stained with Giemsa stain (Sigma-Aldrich, MO, USA). Colonies containing more than 50 cells were counted to determine a surviving fraction.

\subsection{BP1 Foci Formation}

Cells grown on coverslips were incubated with or without 5 $\mu \mathrm{M}$ gemcitabine for $24 \mathrm{~h}$ at $37^{\circ} \mathrm{C}$. After incubation, cells were irradiated with different doses between $0 \sim 6 \mathrm{~Gy}$. At different time intervals after irradiation, cells were fixed using a $3.6 \%$ formaldehyde solution and permeabilized with $0.5 \%$ Triton-X100 in cytoskeleton (CSK) buffer. Subsequently, cells were incubated with a rabbit polyclonal antibody against 53BPI (Bethyl Laboratories, Montgomery, TX, USA) at a concentration of $0.2 \mu \mathrm{l} / 100 \mu \mathrm{l}$ dissolved in TBS-DT (20 mM Tris- $\mathrm{HCl}, 137 \mathrm{mM} \mathrm{NaCl}, 0.1 \%$ Tween $20,125 \mathrm{~g} / \mathrm{ml}$ ampicillin, $5 \%$ skimmed milk) for $2 \mathrm{~h}$. After washing with PBS, samples were incubated with $2 \mu \mathrm{g} / \mathrm{ml}$ secondary antibody conjugated with Alexa Fluor ${ }^{\circledR 594}$ (Molecular Probes, Life Technologies Japan, Tokyo, Japan) for $1 \mathrm{~h}$ and $2 \mu \mathrm{g} / \mathrm{ml}$ 4',6-diamidino-2-phenylindole (DAPI) (Molecular Probes) for $30 \mathrm{~min}$. To analyze the samples, coverslips were mounted onto slide glasses with $10 \%$ glycerol in PBS. Image analysis was performed on overlay projections using a fluorescence microscope (IX81; Olympus, Tokyo, Japan), with a mounted digital camera (DP72, Olympus, Tokyo, Japan). The size of nuclei was analyzed by the value of pixels that occupied the nucleus on digital images of the fluorescence microscope. The number of nuclei was counted on the monitor. Each value was obtained repeatedly at least twenty times to determine average values and standard deviations. 


\subsection{Statistical Analysis}

Significance of the difference was assessed by Student's $t$ test and the Mann-Whitney test. A $p$ value of $<0.05$ was considered statistically significant. A standard deviation is presented in a figure when each assay could be repeated at least three times. Statistical analyses were performed with SPSS (version 19.0; Tokyo, Japan).

\section{Results}

\subsection{The Correction Coefficients to Calculate a Collected Absorbed Dose}

The peak water depth dose from the surface was $2.5 \mathrm{~cm}$ for a $10 \times 10 \mathrm{~cm}^{2}$ field at a source-to face distance of $100 \mathrm{~cm}$ for $10 \mathrm{MeV}$ X-rays. At the peak depth, the correction coefficients were determined from the amount of charge measured in water and the equivalent phantom (Figure 1). Table 1 shows the correction coefficients and the revised MU.

\subsection{DNA Damage and Enlargement of Cells Induced by Gemcitabine}

We observed DNA damage and cell enlargement induced by gemcitabine by staining phosphorylated p53-binding protein 1 (53BP1). 53BP1 is phosphorylated at DNA DSBs; therefore, we counted 53BP1 foci to represent the total number of DSBs. CHO cells were incubated with or without $5 \mu \mathrm{M}$ gemcitabine for $24 \mathrm{~h}$ before immediate fixation, following by immunofluorescence staining for DAPI and 53BP1. Figure 4 shows the overlay projections of 53BP1 and DAPI signals using the fluorescence microscope. The untreated $\mathrm{CHO}$ cells showed a small number of 53BP1 foci scattered in nuclei (Figure 2A), whereas the gemcitabine-treated $\mathrm{CHO}$ cells showed concentrated 53BP1 foci in nuclei (Figure 2B).

The number of 53BP1 foci in nuclei was increased significantly in both in $\mathrm{CHO}$ and xrs5 cells after gemcitabine treatment (Figure 3). In untreated cells, an average of 53 BP1 foci were observed; however, this was significantly increased, by 10.9-fold in CHO cells and 15.8-fold in xrs5 cells, by gemcitabine treatment $(* * * ; p<0.001$ and $p<0.001$, respectively). The number of foci was significantly greater in xrs5 cells compared with $\mathrm{CHO}$ cells after gemcitabine treatment $(* ; p<0.05)$. These data indicate that gemcitabine induces DNA DSBs, the extent of which depends on repair ability.

Next we evaluated cell enlargement by gemcitabine. Nucleus size was evaluated by immunofluorescent visualization and observation of pixel values on a digital screen. Gemcitabine pre-treatment significantly increased the pixel value of nuclei from $2944.4 \pm 247.9$ to $4204.1 \pm 711.3$ (a 1.43-fold increase) in CHO cells, and from 2917.9 \pm 244.8 to $4024.2 \pm 653.6$ (a 1.38-fold increase) in xrs5 cells (Figure 4: $* * * p<0.001)$. These data demonstrate that gemcitabine induces cell enlargement, while the extent of enlargement does not depend on repair ability.

\subsection{Radiosensitivity to Different X-ray Energy}

Strong radiosensitivity was observed in xrs5 cells. Exponentially growing cells were irradiated with different doses ranging from $1 \mathrm{~Gy}$ to $6 \mathrm{~Gy}$ for $\mathrm{CHO}$ cells, and from 0.5 Gy to 2 Gy for xrs5 cells. As shown in Figure 5, the survival of xrs5 cells was the same for the two of X-ray energies. By contrast, $\mathrm{CHO}$ cells irradiated by $10 \mathrm{MeV}$ X-rays showed a higher surviving fraction compared with that irradiated by 150 $\mathrm{keV}$. For irradiation over $4 \mathrm{~Gy}$, the surviving fraction showed a near 1.5-fold increase using high energy X-ray irradiation compared to low energy-irradiated cells. Meanwhile, xrs5 cells showed no difference for the two types of X-ray energy.

\subsection{Effect of Gemcitabine on Radiosensitivity}

The effect of gemcitabine on cellular radiosensitivity is shown in Figure 6. Cells $\left(10^{6} / \mathrm{ml}\right)$ were exposed to graded doses of $10 \mathrm{Mev}$ X-rays with or without a $24 \mathrm{~h}$ pre-incubation of $5 \mu \mathrm{M}$ gemcitabine. Cells showed hyper-radiosensitivity when pretreated with gemcitabine. Unlike the previously mentioned surviving fraction induced by $\mathrm{X}$-irradiation, the surviving fraction induced by $\mathrm{X}$-irradiation with gemcitabine showed an increased radiosensitivity even for xrs5 cells.

\subsection{Elimination Kinetics of 53BP1 Foci Induced by $X$-irradiation with Gemcitabine}

We observed time-dependent changes in 53BP1 foci formation induced by X-irradiation with or without gemcitabine treatment. $\mathrm{CHO}$ and xrs5 cells were incubated with or without $5 \mu \mathrm{M}$ gemcitabine for $24 \mathrm{~h}$, and then exposed to $1 \mathrm{~Gy}$ by $10 \mathrm{Mev}$ X-rays. As seen in Figure 7, the number of DNA DSBs was significantly increased both in $\mathrm{CHO}$ and xrs5 cells $(p<0.001)$ by the use of gemcitabine. When cells were not pretreated with gemcitabine, eventually almost all DNA DSBs induced by X-irradiation disappeared with time. As time progressed, xrs5 cells consistently had a slightly greater number of DNA DSBs than CHO cells. Meanwhile, when pretreated with gemcitabine, many DSBs remained after a certain time. This trend was seen in both $\mathrm{CHO}$ and xrs5 cells. The use of gemcitabine, therefore, increased DNA DSBs and inhibited the disappearance of DSBs with the passage of time. These results indicate that a radiosensitizing effect of gemcitabine inhibits cellular repair. Furthermore, the similar behavior of $\mathrm{CHO}$ and xrsa5 cells indicates the involvement of a DNA repair pathway other than NHEJ.

\section{Discussion}

Gemcitabine is a deoxycytidine analogue that is well known for its antitumor activity. Gemcitabine is phosphorylated intracellularly to its active metabolites (gemcitabineMP, gemcitabineDP, and gemcitabineTP) by deoxycytidine kinase. GemcitabineTP is incorporated into DNA and obstructs DNA replication and repair [21-23]. Meanwhile, ionizing radiation induces an array of lesions in DNA, including base damage, single-strand breaks and DSBs, and damage to the 
phosphodiester backbone. DNA DSBs are potentially dangerous to cells because they may lead to chromosome breakage and loss of genetic information; indeed DSBs are thought to be the most relevant lesion in radiation-induced cell death. In lower eukaryotes, such as yeast, DSBs are repaired by Rad52-dependent homologous recombination (HR). Rad52 binds to DNA ends, thereby protecting them from exonuclease activity and activating end-to-end interaction and HR [24]. In vertebrates, however, DSBs are primarily repaired by $\mathrm{Ku}$-dependent NHEJ. In mammals, NHEJ is the most prominent cellular DNA repair pathway of radiation-induced DNA DSBs [17].

Van Putten et al. previously reported that incubation with gemcitabine alone did not cause DSBs, and preincubation with gemcitabine caused no changes in the induction of radiation-induced DSBs [14]. In this study, we showed that gemcitabine alone induced cell enlargement and caused DNA DSBs. The extent of enlargement did not depend on the ability to repair DSBs, although the number of DNA DSBs induced by gemcitabine depends on the cell's repair ability. Xrs5 cells are rodent cells that carry a mutated $X r c c 5$ gene, which encodes Ku80. Ku80 binds to DNA DSB ends and is required for the NHEJ pathway; therefore, xrs5 cells are deficient in NHEJ repair [25-26]. Because gemcitabine is incorporated into DNA and obstructs DNA replication and repair, the greater effects of gemcitabine in xrs5 cells results from an involvement of the NHEJ repair pathway.

Next we compared the effects of $10 \mathrm{MeV}$ and 150 $\mathrm{keV}-\mathrm{X}$-ray irradiation. In $\mathrm{CHO}$ cells, the surviving fraction was lower after $150 \mathrm{keV}$-X-ray irradiation but there was no difference for xrs5 cells. In mammalian cells, the relative biological effectiveness (RBE), which is a ratio of the biological effects generated by high linear energy transfer (LET) radiation to low LET reference radiation, ranges from 2 to 6 [27]. However, in an NHEJ-deficient genetic background, where HR is the main mechanism for repair, the RBE for high LET radiation is close to 1 [28-29]. This suggests that NHEJ is the most prominent DNA repair pathway of radiation-induced DNA DSBs. Our results are insufficient to fully explain whether low energy X-ray radiation kills more cells at a given dose. However, our findings that xrs5 cells were affected to the same degree by different X-ray energies reflected the fact that radiation-induced DNA DSBs are repaired by the NHEJ pathway.

Meanwhile, gemcitabine-induced radiosensitivity caused increased cell death both in $\mathrm{CHO}$ and xrs5 cells. Gemcitabine enhanced cell killing in both NHEJ-active and -inactive cells. This suggests that the pathways in which gemcitabine is involved could be different for gemcitabine used independently and simultaneously with X-rays. John et al. previously reported that preincubation with gemcitabine caused no changes in the induction of radiation-induced DSBs [14], whereas our results showed that gemcitabine induced radiosensitization even in NHEJ-deficient xrs5 cells. Our data show that the mechanism for gemcitabine-induced radiosensitivity involves a pathway other than NHEJ.

The kinetics of DNA DSBs were studied to reveal the process of DNA DSB repair. We examined the kinetics of gemcitabine-induced radiosensitivity. Gemcitabine increased the occurrence of DNA DSBs, and inhibited the disappearance of DSBs with time. Interestingly the NHEJ-deficient xrs5 cells exhibited a similar tendency as the NHEJ-active cells (CHO). This suggests that the NHEJ pathway is not involved in the gemcitabine mechanism of action for radiosensitization. Wachters et al. [9] reported that they excluded NHEJ as a target for gemcitabine, because the radiosensitizing effect of gemcitabine was also observed in cells lacking either functional DNA-PKcs or Ku80. We reported the possibility that gemcitabine treatment may inhibit the repair pathway of homologous recombination using human pancreatic cancer cells [12]. In this study using mammalian cells, we confirmed that gemcitabine inhibits the repair of radiation-induced DSBs via a pathway other than NHEJ.

Our study had limitations. To clarify the difference between low energy and high energy of X-rays, we need more detailed experimentation. Additionally, a larger sample size would have provided more confirmatory analysis results.

In conclusion, we examined the role of gemcitabine and radiosensitization in rodent cell lines using high-energy X-rays. Gemcitabine alone induced cell enlargement and DNA DSBs. Unlike cell enlargement, the extent of DNA DSBs was dependent on the ability to repair DNA. In rodent cells the radiosensitizing effect of gemcitabine is related to suppression of a repair pathway other than NHEJ. We performed this study using $10 \mathrm{Mev} \mathrm{X}$-rays, which is a novel approach using cultured cells. More detailed studies using $\mathrm{X}$-rays of different energy are needed to determine whether differences in X-ray energy effect the results of cultured cell experiments. However, here, we show the influence of gemcitabine-induced radiosensitivity using a device that is actually used for radiation therapy. Our study reflect actual effects of radiosensitization of gemcitabine to mammalian cells during radiation treatment. Our data therefore support further trials to evaluate the clinical usefulness of gemcitabine in combination with radiation.

\section{Acknowledgements}

This study was supported by a Grant-in-Aid for Scientific Research, Japan (no. 24791317).

\section{Conflict of Interest Statement}

All the authors do not have any possible conflicts of interest.

\section{Human Rights Statement and Informed Consent}

This study was performed by cell culture experiment. All procedures followed were in accordance with the ethical standards of the responsible committee and with the Helsinki Declaration of 1964 and later revision. Informed consent was not needed in the study. 


\section{Appendix}

Figure and Table Legends

Table 1. Correction Coefficients for Irradiation dose and Revised MU.

\begin{tabular}{|c|c|c|c|c|c|c|c|c|c|}
\hline \multirow{2}{*}{$\begin{array}{l}\text { absorbed } \\
\text { dose (Gy) }\end{array}$} & \multirow{2}{*}{$\begin{array}{l}\text { MU } \\
(\mathbf{c G y})\end{array}$} & \multicolumn{6}{|c|}{ electric charge amount (nC) } & \multirow{2}{*}{$\begin{array}{l}\text { correction } \\
\text { coefficients }\end{array}$} & \multirow{2}{*}{$\begin{array}{l}\text { revised } \\
\text { MU (cGy) }\end{array}$} \\
\hline & & water pl & & & equivale & ton & & & \\
\hline 0.5 & 50 & 9.305 & \pm & 0.002 & 8.697 & \pm & 0.007 & 0.935 & 53 \\
\hline 1 & 99 & 18.433 & \pm & 0.006 & 17.17 & \pm & 0.002 & 0.931 & 106 \\
\hline 2 & 198 & 36.886 & \pm & 0.011 & 34.405 & \pm & 0.023 & 0.933 & 212 \\
\hline 4 & 396 & 73.861 & \pm & 0.024 & 68.927 & \pm & 0.002 & 0.933 & 424 \\
\hline 6 & 594 & 110.844 & \pm & 0.021 & 103.687 & \pm & 0.091 & 0.935 & 635 \\
\hline
\end{tabular}

Abbreviation: $\mathrm{MU}=$ monitor unit

Mean with standard error of at least three measurement values.

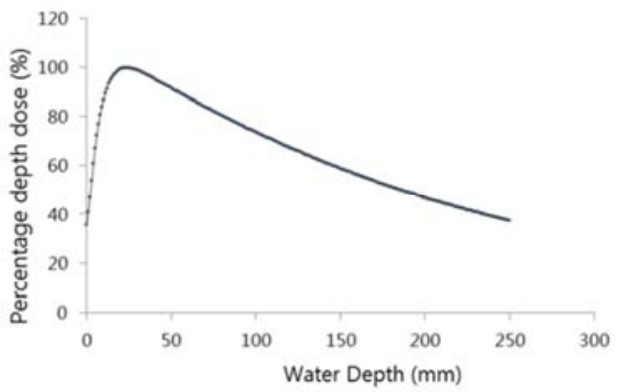

Figure 1. The dose Depth Curve in a Water Phantom with a $10 \times 10 \mathrm{~cm}^{2}$ Field at a Source-to Face Distance of $100 \mathrm{~cm}$ for $10 \mathrm{MeV} X$-rays.
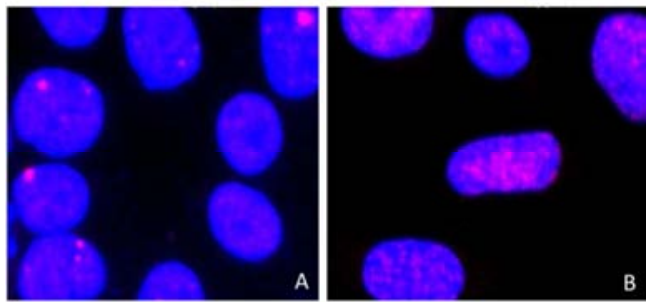

Figure 2. Formation of 53BP1 Foci with or Without Gemcitabine in CHO Cells. CHO Cells Cultured on Cover Slips were Treated with or Without $5 \mu M$ Gemcitabine for $24 \mathrm{~h}$, Following by Immunofluorescence Staining for DAPI and 53BP1. (A) 53BP1 Foci in CHO Cells Without Gemcitabine Treatment. (B) $53 B P 1$ Foci in CHO Cells Treated with $5 \mu M$ Gemcitabine for $24 \mathrm{~h}$.

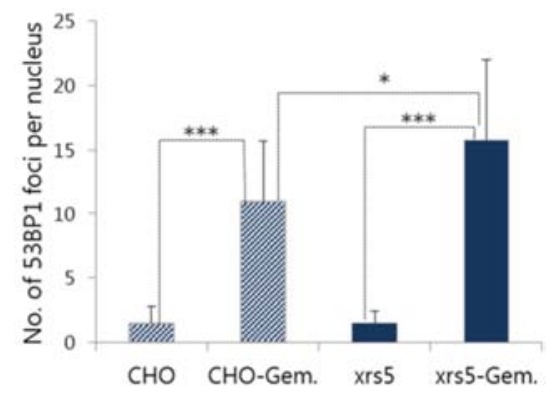

Figure 3. Comparison of the Number of 53BP1 Foci Per Nucleus with and Without Gemcitabine Treatment in CHO or xrs5 Cells. Cells Cultured on Cover Slips were Treated with or Without $5 \mu M$ Gemcitabine for $24 h$, Following by Immunofluorescence Staining for DAPI and 53BP1 at Different Interval Times of $0.25 \mathrm{~h}, 2 \mathrm{~h}$, or $24 \mathrm{~h}$. The Number of Foci Per Nucleus was Calculated on Digital Images. Data Represent the Mean \pm SE of 100 Independent Experiments (*: $p<0.05, * * *: p<0.001)$.

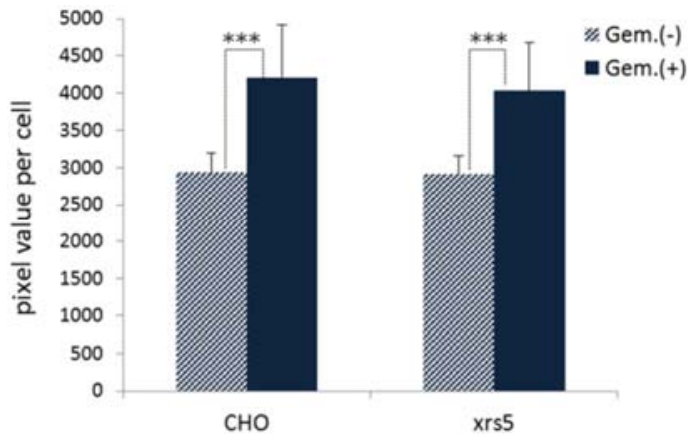

Figure 4. Changes in Nucleus Size Due to Gemcitabine Treatment Visualized by Immunofluorescence. $\mathrm{CHO}$ and xrs 5 Cells Cultured on Cover Slips were Treated with or Without $5 \mu M$ Gemcitabine for $24 \mathrm{~h}$, Following by Immunofluorescence Staining for DAPI. The Nucleus Size was Evaluated by a Pixel Value that Occupied the Nucleus on the Digital Image. Data Represent the Mean \pm SE of 100 Independent Experiments (***: $p<0.001)$.

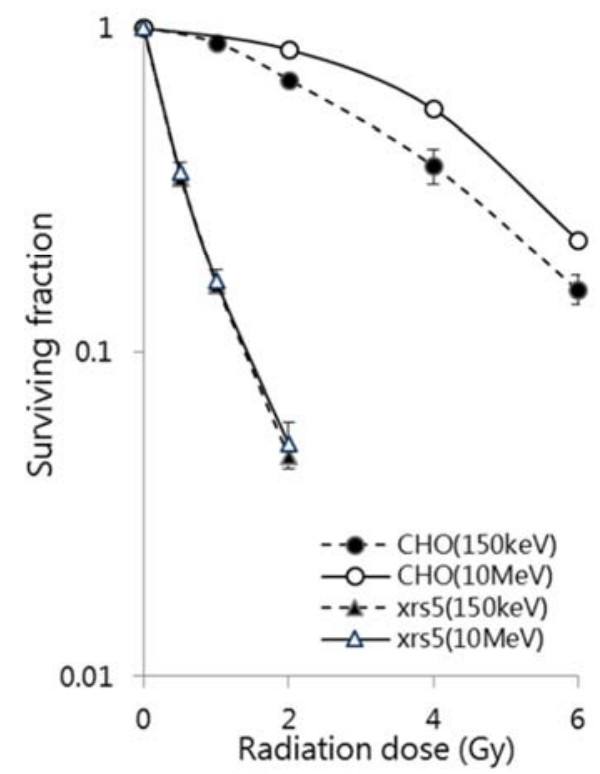

Figure 5. Survival of $\mathrm{CHO}$ and $x \mathrm{rs} 5$ Cells After Irradiation. Cells $\left(10^{6} / \mathrm{ml}\right)$ were Exposed to Different doses from $1 \mathrm{~Gy}$ to $6 \mathrm{~Gy}$ of $10 \mathrm{MeV} X$-rays (O) or $150 \mathrm{keVX}$-rays (•) for $\mathrm{CHO}$ Cells, and from $0.5 \mathrm{~Gy}$ to $2 \mathrm{~Gy}$ of $10 \mathrm{MeVX}$-rays $(\Delta)$ or $150 \mathrm{keV} X$-rays $(\boldsymbol{\Delta})$ for xrs 5 Cells. Means and Standard Deviations are Presented when Three Independent Experiments were Conducted. 


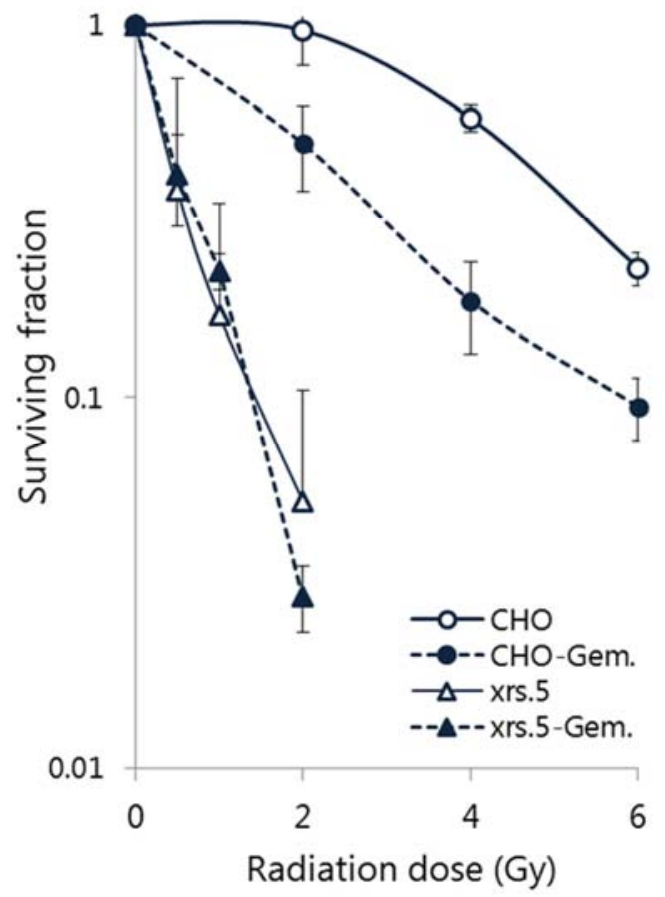

Figure 6. Comparison of the Effect of Gemcitabine on Radiosensitivity of $\mathrm{CHO}$ and xrs 5 Cells Represented by the Surviving Fraction. Cells $(10 \% \mathrm{ml})$ were Exposed to Graded doses of X-rays with or Without a $24 \mathrm{~h}$ Pre-incubation with $5 \mu M$ Gemcitabine. Cell Survival was Assessed by a Colony Formation Assay. Plotted are the Irradiation Effect Without Gemcitabine Pre-incubation of $\mathrm{CHO}(\mathrm{O})$ and xrs5 Cells ( $\Delta)$, Compared with the Effect of Gemcitabine Pre-incubation of $\mathrm{CHO}(\bullet)$ and xrs5 cells $(\mathbf{\Delta})$.

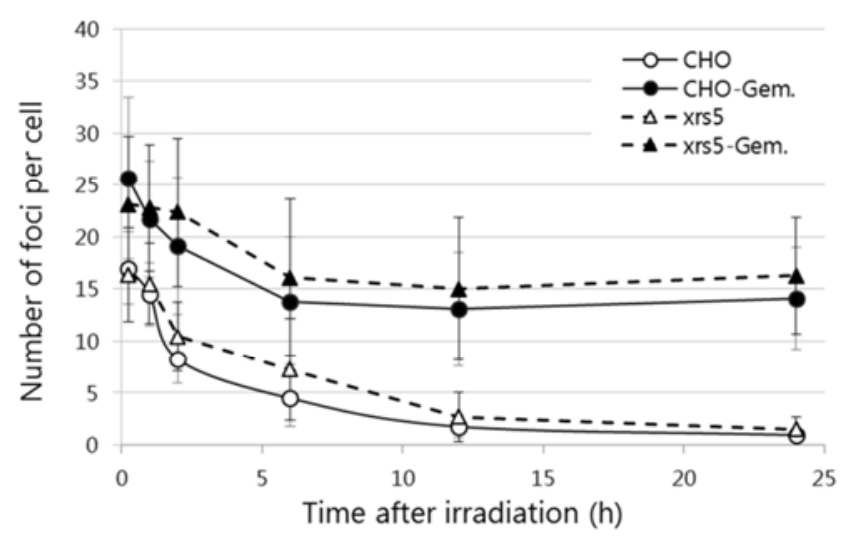

Figure 7. Appearance and Disappearance of 53BP1 Foci After Irradiation with or Without Gemcitabine Pretreatment. CHO and Xrs5cells were Incubated with or Without $5 \mu \mathrm{M}$ Gemcitabine for $24 \mathrm{~h}$ Before Irradiation (1 Gy) Followed by Fixation at Different Intervals. Plotted are the Number of Foci Per Cell Without Gemcitabine Pre-incubation in CHO (०) or xrs5 Cells $(\Delta)$, Compared with the Foci Number with Gemcitabine Pre-incubation in $\mathrm{CHO}(\bullet)$ or xrs 5 cells $(\mathbf{\Lambda})$. The Number of Foci Per Cell is Represented as the Mean Value for 20 cells.

\section{References}

[1] Kwegyir-Afful AK, Murigi FN, Purushottamachar P, Ramamurthy VP, Martin MS, Njar VCO. Galeterone and its analogs inhibit Mnk-eIF4E axis, synergize with gemcitabine, impede pancreatic cancer cell migration, invasion and proliferation and inhibit tumor growth in mice. Oncotarget. 2016, 8(32): 52381-402.
[2] Zhang SH, Liu GF, Li XF, Liu L, Yu SN. Efficacy of different chemotherapy regimens in treatment of advanced or metastatic pancreatic cancer: a network meta-analysis. J Cell Physiol. 2017, Sep 19. doi: 10.1002/jep.26183.

[3] Rajabpour A, Afgar A, Mahmoodzadeh H, Radfar JE, Rajaei F, Teimoori-Toolabi L. MiR-608 regulating the expression of ribonucleotide reductase $\mathrm{M} 1$ and cytidine deaminase is repressed through induced gemcitabine chemoresistance in pancreatic cancer cells. Cancer Chemother Pharmacol. 2017 Sep 8. doi: 10.1007/s00280-017-3418-2.

[4] Schwartzberg LS, Arena FP, Bienvenu BJ, Kaplan EH, Camacho LH, Campos LT, Waymack JP, Tagliaferri MA, Chen MM, Li D. A Randomized, Open-Label, Safety and Exploratory Efficacy Study of Kanglaite Injection (KLTi) plus Gemcitabine versus Gemcitabine in Patients with Advanced Pancreatic Cancer. J Cancer. 2017, 8(10): 1872-83.

[5] Shewach DS, Hahn TM, Chang E, Hertel LW, Lawrence TS. Metabolism of 2',2'-difluoro-2'-deoxycytidine and radiation sensitization of human colon carcinoma cells. Cancer Res. 1994, 54(12): 3218-23

[6] Lawrence TS, Chang EY, Hahn TM, Hertel LW, Shewach DS. Radiosensitization of pancreatic cancer cells by 2',2'-difluoro-2'-deoxycytidine. Int J Radiat Oncol Biol Phys. 1996, 34(4): 867-72.

[7] Joschko MA, Webster LK, Groves J, Yuen K, Palatsides M, Ball DL, Millward MJ. Enhancement of radiation-induced regrowth delay by gemcitabine in a human tumor xenograft model. Radiat Oncol Investig. 1997, 5(2): 62-71.

[8] Milas L, Fujii T, Hunter N, Elshaikh M, Mason K, Plunkett W, Ang KK, Hittelman W. Enhancement of tumor radioresponse in vivo by gemcitabine. Cancer Res. 1999, 59(1): 107-14.

[9] Wachters FM, van Putten JW, Maring JG, Zdzienicka MZ, Groen HJ, Kampinga HH. Selective targeting of homologous DNA recombination repair by gemcitabine. Int J Radiat Oncol Biol Phys. 2003, 57(2): 553-6.

[10] Wouters A, Pauwels B, Lambrechts HA, Pattyn GG, Ides J, Baay M, Meijnders P, Peeters M, Vermorken JB, Lardon F. Retention of the in vitro radiosensitizing potential of gemcitabine under anoxic conditions, in p53 wild-type and p53-deficient non-small-cell lung carcinoma cells. Int J Radiat Oncol Biol Phys. 2011, 80(2): 558-66.

[11] Shen ZT, Wu XH, Wang L, Li B, Zhu XX. Effects of gemcitabine on radiosensitization, apoptosis, and Bcl-2 and Bax protein expression in human pancreatic cancer xenografts in nude mice. Genet Mol Res. 2015, 14(4): 15587-96.

[12] Kobashigawa S, Morikawa K, Mori H, Kashino G. Gemcitabine Induces Radiosensitization Through Inhibition of RAD51-dependent Repair for DNA Double-strand Breaks. Anticancer Res. 2015, 35(5): 2731-7.

[13] Im MM, Flanagan SA, Ackroyd JJ, Knapp B, Kramer A, Shewach DS. Late DNA Damage Mediated by Homologous Recombination Repair Results in Radiosensitization with Gemcitabine. Radiat Res. 2016, 186(5): 466-77.

[14] van Putten JWG, Groen HJM, Smid K, Peters GJ, Kampinga $\mathrm{HH}$. End-joining deficiency and radiosensitization induced by gemcitabine. Cancer Res. 2001, 61(4): 1585-91.

[15] Lawrence T. S, Eisbruch A, Shewach D. S. Gemcitabine-mediated radiosensitization. Semin. Oncol. 1997, 24(7): 24-8. 
[16] Gospodinov A, Herceg Z. Chromatin structure in double strand break repair. DNA Repair (Amst). 2013, 12(10): 800-10.

[17] Kanaar R, Hoeijmakers JH, van Gent DC. Molecular mechanisms of DNA double strand break repair. Trends Cell Biol. 1998, 8: 483-9.

[18] Karran P. DNA double strand break repair in mammalian cells. Curr Opin Genet Dev. 2000, 10: 144-50.

[19] Khanna KK, Jackson SP. DNA double-strand breaks: signaling, repair and the cancer connection. Nat Genet. 2001, 27: 247-54

[20] Japan society of medical physics, Committee of Dosimetry. Standard Dosimetry of Absorbed in Dose in External Beam Radiotherapy. Tokyo: Tushosangyoukenkyusya; 2006. P. $35-46$.

[21] Tashiro S, Walter J, Shinohara A, Kamada N, Cremer T. Rad51 accumulation at sites of DNA damage and in postreplicative chromatin. J Cell Biol. 2000, 150(2): 283-91.

[22] Schy WE1, Hertel LW, Kroin JS, Bloom LB, Goodman MF, Richardson FC. Effect of a template-located 2',2'-difluorodeoxycytidine on the kinetics and fidelity of base insertion by Klenow (3'-->5'exonuclease-) fragment. Cancer Res. 1993, 53(19): 4582-7.

[23] Ross GM, Eady JJ, Mithal NP, Bush C, Steel GG, Jeggo PA, McMillan TJ. DNA strand break rejoining defect in xrs-6 is complemented by transfection with the human Ku80 gene. Cancer Res. 1995, 55(6): 1235-8.
[24] Van Dyck E, Stasiak AZ, Stasiak A, West SC. Binding of double-strand breaks in DNA by human Rad52 protein. Nature. 1999, 398(6729): 728-31.

[25] Singleton BK, Priestley A, Steingrimsdottir H, Gell D, Blunt T, Jackson SP, Lehmann AR, Jeggo PA. Molecular and biochemical characterization of xrs mutants defective in $\mathrm{Ku} 80$. Mol Cell Biol. 1997, 17(3): 1264-73.

[26] He DM, Lee SE, Hendrickson EA. Restoration of X-ray and etoposide resistance, $\mathrm{Ku}$-end binding activity and V(D) J recombination to the Chinese hamster sxi-3 mutant by a hamster Ku86 cDNA. Mutat Res. 1996, 363(1): 43-56.

[27] Wang H, Wang X, Chen G, Zhang X, Tang X, Park D, Cucinotta FA, Yu DS, Deng X, Dynan WS, Doetsch PW, Wang Y. Distinct roles of Ape1 protein, an enzyme involved in DNA repair, in high or low linear energy transfer ionizing radiation-induced cell killing. J Biol Chem. 2014 Oct 31;289(44):30635-44. doi: 10.1074/jbc.M114.604959.

[28] Okayasu R, Okada M, Okabe A, Noguchi M, Takakura K, Takahashi S. Repair of DNA damage induced by accelerated heavy ions in mammalian cells proficient and deficient in the non-homologous end-joining pathway. Radiat Res. 2006, 165(1): 59-67.

[29] Wang H1, Wang X, Zhang P, Wang Y. The Ku-dependent non-homologous end-joining but not other repair pathway is inhibited by high linear energy transfer ionizing radiation. DNA Repair (Amst). 2008, 7(5): 725-33. 